\title{
PERFIL E IMPACTO SOCIOECONÓMICO DOS ESTUDANTES NAS ESCOLAS POLITÉCNICAS DO INTERIOR DE PORTUGAL - O CASO DE ESTUDO DA ESTH-IPG
}

PROFILE AND SOCIOECONOMIC IMPACT OF STUDENTS IN POLITECHNIC SCHOOLS OF THE INTERIOR OF PORTUGAL THE ESTH-IPG CASE STUDY

PERFIL E IMPACTO SOCIOECONÓMICO DE LOS ESTUDIANTES EN LAS ESCUELAS POLITÉCNICAS DEL INTERIOR DE PORTUGAL - EL CASO DE ESTUDIO DE LA ESTH-IPG

Romeu Lopes (Romeu_lopes@ipg.pt)*

José Alexandre Martins (jasvm@ipg.pt)**

Vítor Roque (vitor.roque@ipg.pt) ${ }^{\star \star \star}$

\section{RESUMO}

Nos últimos anos, algumas instituições de ensino superior, em particular as do interior, têm encontrado dificuldades em captar e fixar novos alunos, em consequência de um processo de litoralização continuado. Nesse sentido, com esta investigação pretende-se caraterizar o perfil socioeconómico dos estudantes da Escola Superior de Turismo e Hotelaria (ESTH) do Instituto Politécnico da Guarda (IPG) e o "valor" que representam para o concelho de Seia. Como objetivos gerais da investigação, salientam-se os seguintes: (i) conhecer o perfil dos alunos; (ii) percecionar as condições e limitações de vida que a região e a instituição oferecem; (iii) indagar sobre as perspetivas de futuro em termos profissionais. O método escolhido foi o da pesquisa quantitativa, realizada essencialmente de forma descritiva e centrada na análise e interpretação dos dados, recolhidos através de um questionário em suporte de papel. Este foi distribuído por todos os anos dos cursos em funcionamento. Recolheram-se e validaram-se 252 inquéritos, que foram tratados com recurso ao IBM SPSS Statistics (versão 24). O estudo efetua uma reflexão e disponibiliza um conjunto de sugestões, que podem vir a ser úteis para uma melhor resposta das instituições de ensino superior e do meio envolvente, no sentido de captar e fixar estudantes e futuros 
profissionais, em particular nas regiões do interior do país.

Palavras-chave: Ensino Superior; Escola Superior de Turismo e Hotelaria; Impacto Socioeconómico; Instituto Politécnico da Guarda; Interior.

\section{ABSTRACT}

In recent years, some higher education institutions, particularly those from Inland Portugal, have faced difficulties in attracting and retaining new students due to a process of continuous displacement to the coastal areas. This research intends to characterize the students' socio-economic profile of the Higher School of Tourism and Hotel Management - Polytechnic Institute of Guarda, and point out their "value" to the municipality of Seia. The general objectives of this research are: (i) to know the students' profile; (ii) to perceive their living conditions and limitations that the region and the institution offer; (iii) to inquire about their Professional prospects. The quantitative research method has been selected, carried out essentially in a descriptive way, and centered in the analysis and interpretation of the data collected through a questionnaire on paper. The questionnaires were distributed to all ongoing courses. 252 surveys were collected, validated and treated using IBM SPSS Statistics (version 24). The study makes a reflection and proposes a set of suggestions, which may be useful for a better action from higher education institutions and the nearby environment, in order to attract and settle students and future professionals, particularly those in the interior regions of Portugal.

Keywords: Higher Education; Interior; Polytechnic of Guarda; School of Tourism and Hospitality Management; Socioeconomic Impact.

\section{RESUMEN}

En los últimos años, algunas instituciones de enseñanza superior, en particular las del interior, han encontrado dificultades para captar y fijar nuevos alumnos, en un proceso de litoralización continuado. Con esta investigación se pretende caracterizar el perfil socioeconómico de los estudiantes de la Escuela Superior de Turismo y Hostelería del Politécnico de Guarda y el "valor" que ellos representan para el municipio de Seia. Como objetivos generales de la investigación se destacan los siguientes: conocer el perfil de los alumnos; percibir las condiciones y 
limitaciones de vida que la región y la institución ofrecen; indagar sobre las perspectivas de futuro en términos profesionales. El método elegido fue la investigación cuantitativa, realizada esencialmente de forma descriptiva y centrada en el análisis e interpretación de los datos recogidos a través de un cuestionario en soporte de papel. Este fue distribuido por todos los años de las titulaciones en funcionamiento. Se recopilaron y validaron 252 encuestas, que fueron tratadas con IBM SPSS Statistics (versión 24). El estudio efectúa una reflexión y ofrece un conjunto de sugerencias que pueden resultar útiles para una mejor respuesta de las instituciones de enseñanza superior y del entorno, en el sentido de captar y fijar estudiantes y futuros profesionales, en especial en las regiones del interior de Portugal.

Palabras clave: Enseñanza Superior; Escuela Superior de Turismo y Hostelería; Impacto Socioeconómico; Interior; Instituto Politécnico de Guarda.

* Professor Adjunto da Escola Superior de Turismo e Hotelaria (ESTH) do Instituto Politécnico da Guarda (IPG), Portugal. Membro da UTC de Turismo e Hotelaria do IPG. Membro da Unidade de Investigação para o Desenvolvimento do Interior (UDI/IPG).

** Professor Adjunto da Escola Superior de Turismo e Hotelaria (ESTH) do Instituto Politécnico da Guarda (IPG), Portugal. Membro da UTC de Ciências Exatas e Experimentais do IPG. Membro da Unidade de Investigação para o Desenvolvimento do Interior (UDI/ IPG).

*** Professor Adjunto da Escola Superior de Turismo e Hotelaria (ESTH) do Instituto Politécnico da Guarda (IPG), Portugal. Membro da UTC de Turismo e Hotelaria do IPG. Membro da Unidade de Investigação para o Desenvolvimento do Interior (UDI/IPG). 


\section{INTRODUÇÃO}

Atualmente, com a democratização no acesso ao Ensino Superior (ES), assiste-se a uma maior diversidade sociocultural dos estudantes que o frequentam, nas suas motivações e expectativas, não só em Portugal como em outras regiões do globo (Araújo et al., 2015; Soares et al., 2014).

O número de ingressos no Ensino Superior (ES) em Portugal tem aumentado na última década. De acordo com os dados oficiais da Direção Geral do Ensino Superior, em 20061 ocorreram 49006 candidaturas para um total de 46528 vagas. Comparativamente, em 20162 registaram-se 56417 candidaturas (+15,1\%), para um total de 50688 vagas (+8,9\%). No entanto este aumento não é sentido por todas as Instituições de Ensino Superior (IES), em particular as localizadas em regiões do interior, que têm encontrado dificuldades em captar e fixar novos alunos, devido a um processo de litoralização continuado.

Na verdade, as expectativas académicas, aqui entendidas como os objetivos e motivações que sustentam a candidatura dos estudantes ao ensino superior, são determinantes para o sucesso da transição e adaptação a uma nova realidade. Expectativas académicas elevadas parecem estar associadas a melhores índices de adaptação académica (Soares et al., 2014). No entanto, por vezes essas expectativas são muito elevadas e revelam algum "desconhecimento e ilusões sobre o ES, que seria interessante atenuar aquando do ingresso, sob pena de a desilusão se instalar, dificultando a adaptação dos estudantes ao novo contexto académico" (Araújo et al., 2015, p. 214).

A empregabilidade é também um critério importante a ter em conta na escolha das instituições de ensino superior (IES) e respetivos ciclos de estudo. O conceito de empregabilidade ganhou ainda mais destaque após a adoção de procedimentos de reforma e reorganização do ES no espaço europeu. De facto, a melhoria deste indicador é um dos objetivos fulcrais do Processo de Bolonha, iniciado há mais de uma década. A empregabilidade acaba por ser o resultado de um conjunto de experiências, competências e qualificações, adquiridas em função das motivações e escolhas dos estudantes. No entanto este processo

1 http://www.dges.mctes.pt/guias/pdfs/statcol/2006/Resumo06.pdf

2 http://www.dges.mctes.pt/estatisticasacesso/2016/ 
envolve outros intervenientes, designadamente as instituições de ensino, as entidades empregadoras e o próprio meio envolvente (Cardoso et al., 2012).

As IES são organizações de elevada importância financeira e social, garantindo oportunidades educacionais, económicas, sociais e culturais para as pessoas e regiões onde se inserem, especialmente para as mais despovoadas, como é o caso das localizadas no interior do país (Fernandes, Cunha, \& Oliveira, 2014; Moura, 2014; Rei et al., 2013). Vários estudos (Fernandes, 2009; Oliveira, Cunha, Silva, Lucas \& Nicolau, 2012; Carvalho, Nunes \& Pinto, 2013; Pereira, Alves \& Mourato, 2014; e Moura, 2014), têm destacado o papel fulcral das diversas IES, como mecanismo de desenvolvimento regional. Estas contribuem, também, para o acesso ao ensino superior dos estudantes que de outra forma não teriam estudado numa IES longe da sua residência. No entanto, apesar destas evidências, muitas instituições estão correntemente sob grande pressão para justificar o seu valor à sociedade, devido às atuais dificuldades económicas e às reduções orçamentais. Precisam, portanto, de quantificar o impacto que as suas atividades têm na comunidade onde se inserem.

\section{CONTEXTUALIZAÇÃO}

O presente estudo poderá retratar a realidade de muitas escolas politécnicas do interior de Portugal. Todavia o ponto de partida para análise, e que serviu de base ao mesmo, é a Escola Superior de Turismo e Hotelaria (ESTH), localizada na cidade de Seia. Trata-se de uma das quatro unidades orgânicas do Instituto Politécnico da Guarda (IPG), e a única que está localizada fora da capital de distrito.

No que concerne à procura estudantil, entre 2013 e 2017, tendo como referência três cursos de licenciatura, candidataram-se à ESTH 1336 estudantes, foram colocados 372, e destes, 39\% selecionaram a ESTH como primeira opção no concurso nacional de acesso. Esta preferência tem-se acentuado nos últimos anos, tendo registado um aumento de 84,2\% no período em análise. Todavia, o número de alunos colocados não se traduz na sua totalidade em alunos matriculados. Muitos, acabam por optar pelo Ensino Superior Privado, indicando como moti- 
vos a maior proximidade geográfica com a zona de residência, e/ou com as áreas metropolitanas de Lisboa e Porto3.

Importa salientar que a cidade de Seia tem uma localização privilegiada do ponto de vista do Turismo. É frequentemente referida como a porta de entrada para o Parque Natural da Serra da Estrela, reconhecido pela sua biodiversidade, e por uma identidade geológica assente nas rochas graníticas e xistosas. Possui recursos únicos, como o queijo Serra da Estrela, de tipo artesanal, aqui produzido de acordo com condições favoráveis de temperatura e humidade atmosféricas. Contudo, esta localização não tem conseguido atrair investimentos significativos. Atualmente o setor de atividade com mais expressão é o setor terciário. No entanto, durante muitas décadas, a indústria foi o sector que empregou grande parte da população. Em finais da década de 80 surgiram os primeiros sinais da crise dos têxteis, que se agravou nos anos seguintes, arrastando para o desemprego muitas familias (Martinho, 2017).

De acordo com alguns sociólogos, "o principal problema de Seia no presente, é o envelhecimento da população. É causada por uma quebra muito acentuada na natalidade e, por outro lado, pelas migrações internas e internacionais dos grupos de 19-49 anos" (Martinho, 2017, p. 329). Nos últimos anos tem sido registada uma quebra demográfica no interior do país, e a região não tem escapado a essa realidade. O concelho de Seia perdeu cerca de 4000 habitantes numa década (281444 habitantes em 2001, contra os 247025 registados em 2011). Como vimos, esta assimetria regional, interior vs litoral, não é exclusiva do mapeamento do ensino superior, mas também é conhecida a propósito da distribuição da população nacional. Esta situação configura uma realidade dual e profundamente assimétrica no país, com caraterísticas estruturais, geralmente penalizadoras para as regiões e territórios localizados no interior do país (Pereira, Alves \& Mourato 2014), que urge analisar e corrigir.

3 Informações obtidas na sequência do contacto estabelecido entre os serviços académicos da ESTH e os alunos colocados na IES.

4 https://www.ine.pt/xportal/xmain? xpid=INE\&xpgid=ine_publicacoes\&PUBLICACOESpub_boui=37771 1 \&PUBLICACOEStema $=55466 \&$ PUBLICACOESmodo $=2$

5 https://www.ine.pt/xportal/xmain? xpid=INE\&xpgid=ine_publicacoes\&PUBLICACOESpub_boui=156644135\&PUBLICACOEStema $=55466 \&$ PUBLICACOESmodo $=2$ 


\section{METODOLOGIA}

Tendo em conta o enquadramento anterior, com este estudo de natureza descritiva, pretende-se caraterizar o perfil socioeconómico dos estudantes da Escola Superior de Turismo e Hotelaria do Instituto Politécnico da Guarda, e o "valor" que os mesmos representam para a cidade e concelho de Seia.

Em termos globais pretende-se:

(i) conhecer o perfil dos estudantes;

(ii) percecionar as condições e limitações de vida que a região e a instituição oferecem;

(iii) indagar sobre as perspetivas de futuro em termos profissionais, nomeadamente a intenção de fixação na região.

Como método de pesquisa foi escolhida a pesquisa quantitativa uma vez que o pretendido foi analisar, classificar e medir, a vários níveis, a passagem dos estudantes pela ESTH e pela cidade e município de Seia. O estudo centrou-se na análise e interpretação dos dados recoIhidos através de um questionário em suporte de papel.

O questionário foi dividido em quatro grupos de questões. Inicialmente a caraterização pessoal, com 7 questões e o percurso escolar, com 9 questões. Segue-se um grupo de questões (13) relacionadas com as condições de vida dos estudantes, e por fim a caraterização familiar, com 3 questões.

O questionário foi distribuído no período de 13 de junho de 2016 a 22 de julho de 2016 por todos os anos dos ciclos de estudo em funcionamento. De acordo com os dados recolhidos junto dos Serviços Académicos da ESTH, no ano letivo 2015/2016 estavam matriculados nesta Unidade Orgânica (UO) 316 estudantes6. Assim, a análise descritiva teve por base 252 (79,7\%) inquéritos recolhidos e validados, tendo os mesmos sido tratados com o recurso ao IBM SPSS Statistics (versão 24). Com este software, para além da análise descritiva, fez-se o cruzamento de variáveis aplicando o teste do qui-quadrado para a independência das variáveis, bem como a medida de associação V de Cramer. Com este estudo, pretende-se caraterizar o perfil socioeconómico dos estudantes de uma $\cup O$ pertencente a um Instituto Politécnico situado

6 Nesta contabilização não estavam incluídos os alunos em mobilidade Erasmus (incoming). 
no interior de Portugal. Espera-se que desta análise possam emergir algumas forças e fraquezas existentes na ESTH, bem como eventuais ameaças e oportunidades que se poderão colocar à instituição prove-

nientes da sua envolvente. Assim, em última análise, esta investigação pretende também encontrar algumas sugestões no sentido de captar e fixar, em regiões do interior, estudantes e futuros profissionais nas áreas do turismo. Nesse sentido, os resultados do estudo poderão ser benéficos também para outras IES congéneres do interior do país.

\section{ANÁLISE DE DADOS}

Relativamente à caracterização pessoal dos 252 inquiridos validados, constata-se que 52\% são do sexo feminino e que as suas idades variam entre os 17 e os 52 anos, apresentando uma média de 23 anos (com desvio padrão 6,25).

Por outro lado, quase 92\% dos inquiridos indicaram ter nacionalidade portuguesa, e 21 alunos (8,3\%) indicaram outras nacionalidades. 0 distrito de residência habitual fora do período de aulas (Gráfico 1), está concentrada nos distritos da Guarda $(27,7 \%)$, de Coimbra $(21,3 \%)$ e de Viseu (13,3\%), e 37,35\% dos distritos limítrofes, correspondendo a 47,4\% do Interior7 e 52,6\% do Litoral. Já no período de aulas a residência habitual dos alunos é maioritariamente no distrito da Guarda, presumivelmente a maioria deles em Seia, com 90,4\% dos respondentes. Houve 6\% que indicaram Coimbra e 1,6\% que indicaram Viseu, que são distritos limítrofes. Há ainda estudantes que, durante o período letivo, residem em distritos como Aveiro (1,2\%), Porto $(0,4 \%)$ e Setúbal $(0,4 \%)$.

7 Neste grupo foi incluído o Arquipélago dos Açores por sem poucos estudantes e por se considerar que as características socioeconómicas das llhas se aproximam mais das do Interior do que das do Litoral. 


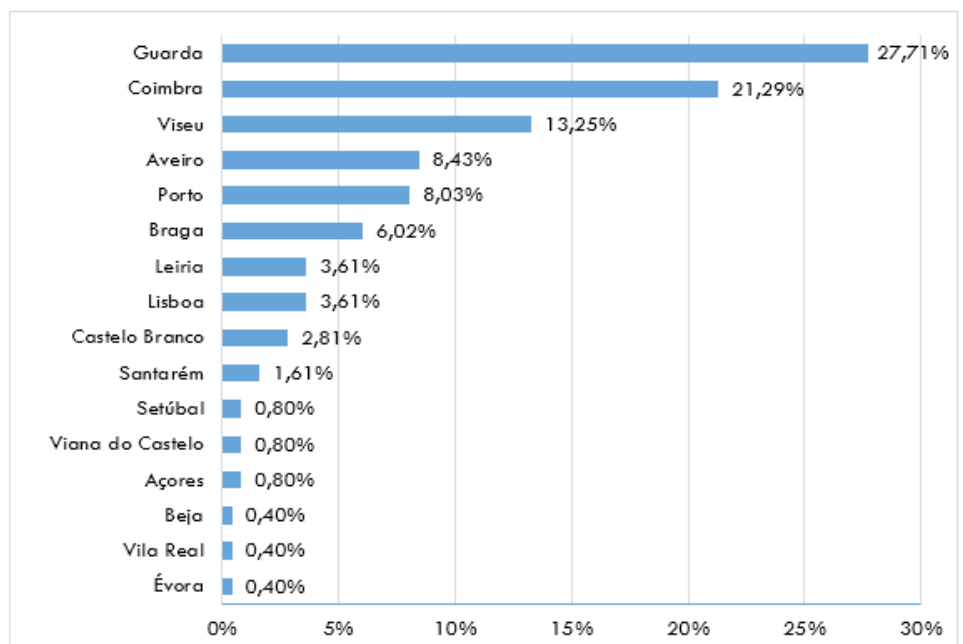

Gráfico 1: Distribuição por distrito de residência habitual fora do período de aulas.

Relativamente ao percurso escolar dos respondentes a maioria $(82,1 \%)$ está inscrita numa licenciatura, 15,5\% inscritos em Cursos Técnicos Superiores Profissionais (CTeSP) e 2,4\% em mestrado. A maioria (90\%) dos respondentes tem o estatuto de aluno ordinário, 8\% o estatuto de trabalhador-estudante e 2\% o de dirigente associativo. Dos 206 inscritos numa licenciatura, 31,3\% estão inscritos no curso de Gestão Hoteleira, 26,2\% são do curso de Turismo e Lazer e 21,4\% pertencem ao curso de Restauração e Catering. Na globalidade dos 206 alunos, $32,5 \%$ frequenta $\circ 1^{\circ}$ ano, $46,1 \% \circ 2^{\circ}$ ano e $21,4 \% \circ 3^{\circ}$ ano dos respetivos cursos.

No que concerne a experiência de trabalho, 43\% dos respondentes indicaram não ter ainda qualquer experiência, 36,5\% afirmam ter já experiência de trabalho na área do curso, e 20,5\% experiência fora da área de formação. Os estágios curriculares estão incluídos nestas experiências, uma vez que como atividade remunerada apenas 17,4\% indicou ter sido na área e 9,7\% fora da área.

Um dos resultados que está relacionado com o impacto económico dos alunos na cidade/região diz respeito às condições de vida. Constata-se desde logo que, excetuando 3 não respostas, 78,3\% dos inquiridos arrendam o local de habitação (48,2\% em casa/apartamento arrendado de forma partilhada, 24,5\% em quarto arrendado e 5,6\% casa/apartamento arrendado sozinho/a).

Em termos de fins de semana passados em Seia, em média mensal 
e por semestre, dos 233 que responderam apenas 8,7\% indicaram nunca ficar em Seia no fim de semana. As respostas com maior representatividade assinalam 1 ou 2 fins de semana, representando 24,2\% e 24,6\% respetivamente. Todavia as opções relacionadas com 3 ou 4 fins de semana são também bastante indicadas, representando 14,7\% e $15,9 \%$ respetivamente.

No que diz respeito ao rendimento médio mensal disponível, as 173 respostas mostram uma média de 308,86€ (com desvio padrão 376,53). Convém recordar que alguns alunos já trabalham, pelo que indicaram rendimentos elevados. Contudo, pelo menos 50\% dos alunos indicaram $160 €$ ou menos, e cerca de $75 \%$ referiram $380 €$ ou menos (os dados por classes estão agrupados no Gráfico 2).

Pode ainda concluir-se que não há diferenças estatísticas significativas quanto ao rendimento médio mensal disponível entre os alunos do litoral e os do interior (significância aproximada de 0,983>0,05), bem como em relação ao género (significância aproximada de 0,982>0,05) (Pestana \& Gageiro, 2014). Da mesma forma, também se conclui que não há diferenças estatísticas significativas quanto ao rendimento médio mensal disponível entre os alunos do sexo masculino e as do sexo feminino. Relativamente aos alunos das licenciaturas, também se conclui que não há diferenças estatísticas significativas quanto ao rendimento médio mensal disponível entre os alunos dos vários anos (significância aproximada de 0,692>0,05). 


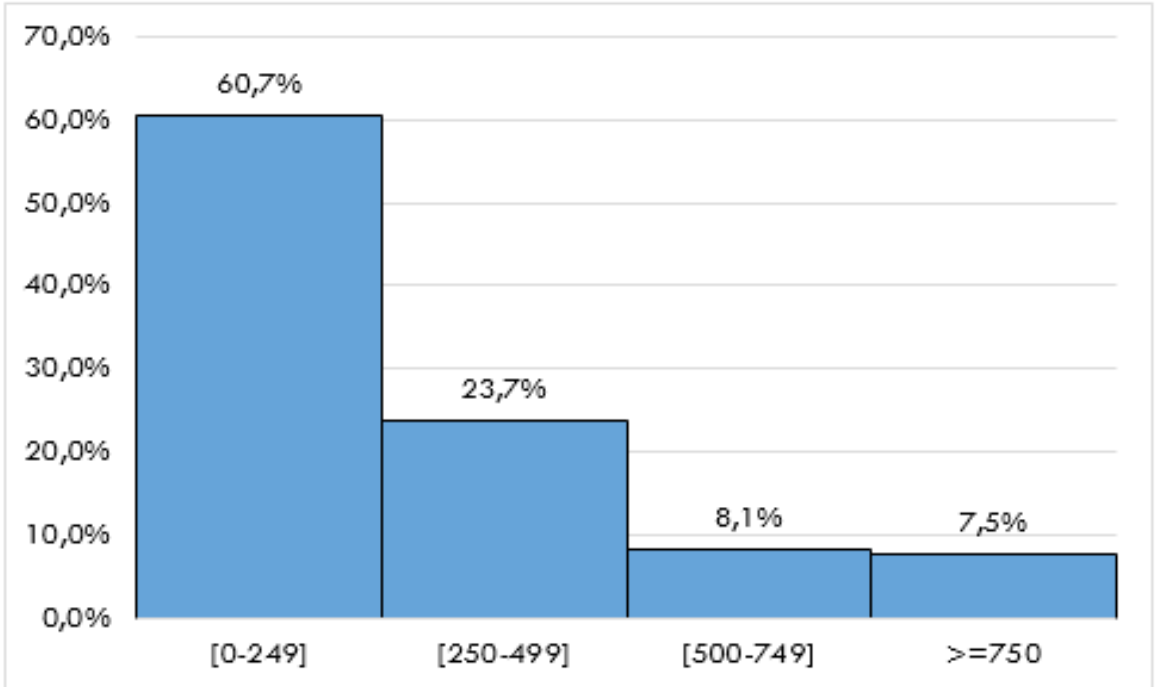

Gráfico 2: Distribuição por classes do rendimento médio disponível.

Ainda no que diz respeito ao rendimento médio mensal disponível, e apesar do número elevado de não respostas ( $N=81 ; 32,1 \%)$, constata-se da análise da Tabela 1 que a fonte maioritária desse rendimento é a familia, seguida da bolsa escolar, trabalho e outras fontes, sendo residual o empréstimo. Alguns alunos indicaram mais que uma opção, havendo $47(27,5 \%)$ a indicarem duas fontes de rendimento e $9(5,3 \%)$ a indicarem três fontes de rendimento.

\begin{tabular}{|c|c|c|c|c|c|c|}
\hline \multicolumn{2}{|c|}{ Rendimento Mensal } & Família & Empréstimo & Bolsa & Trabalho & Outras Fontes \\
\hline \multirow[t]{2}{*}{$\mathrm{N}$} & Válido & 147 & 3 & 43 & 33 & 13 \\
\hline & Omisso & 105 & 249 & 209 & 219 & 239 \\
\hline \multicolumn{2}{|l|}{ Média } & 293,14 & 183,33 & 306,23 & 383,64 & 428,85 \\
\hline \multicolumn{2}{|c|}{ Desvio padrão } & 233,71 & 104,08 & 246,65 & 465,84 & 448,94 \\
\hline \multirow[t]{3}{*}{ Percentis } & 25 & 150,00 & 100,00 & 153,00 & 110,00 & 67,50 \\
\hline & 50 & 250,00 & 150,00 & 240,00 & 200,00 & 300,00 \\
\hline & 75 & 380,00 & & 345,00 & 400,00 & 637,50 \\
\hline
\end{tabular}

Tabela 1: Distribuição e estatísticas em função da fonte de rendimento mensal.

Em termos dos gastos médios mensais realizados pelos 176 estudantes respondentes (69,84\%), obteve-se uma média de 405,08€ (com desvio padrão 232,47). Trata-se de um valor superior ao rendimento 
médio indicado, o que pode mostrar alguma incoerência. Esta situação pode estar relacionada com o facto de, no total de gastos, estar incluída a rúbrica relacionada com o valor das propinas. Este é de aproximadamente $100 €$ e corresponde sensivelmente ao diferencial entre a média do rendimento disponível e a média total de gastos.

Agrupando os dados por classes (Gráfico 3), percebe-se que 64,2\% indicam um gasto médio mensal maior ou igual a $250 €$ e menor que 500€. Já 16,48\% indicam gastar menos de $250 €$ e 19,32\% referem um valor igual ou superior a $500 €$.

Pode ainda concluir-se que não há diferenças estatísticas significativas quanto ao gasto médio mensal entre os alunos do litoral e os do interior (significância aproximada de 0,531>0,05). 0 mesmo sucede em relação ao género (significância aproximada de 0,778>0,05), pelo que se pode também concluir que não há diferenças estatísticas significativas quanto ao gasto médio mensal entre os alunos do sexo masculino e as do sexo feminino. Todavia, se analisado o gasto médio mensal entre os alunos dos vários anos das licenciaturas, constata-se existirem diferenças estatísticas significativas (significância aproximada de 0,01<0,05). Na sequência deste último resultado, parece haver uma tendência para um gasto superior nos estudantes do $3^{\circ}$ ano do que nos do $1^{\circ}$ e $2^{\circ}$ anos. Contudo, o valor $V$ de Cramer, $V=0,234$, indica que existe uma associação fraca entre as duas variáveis, devido ao seu baixo valor. 


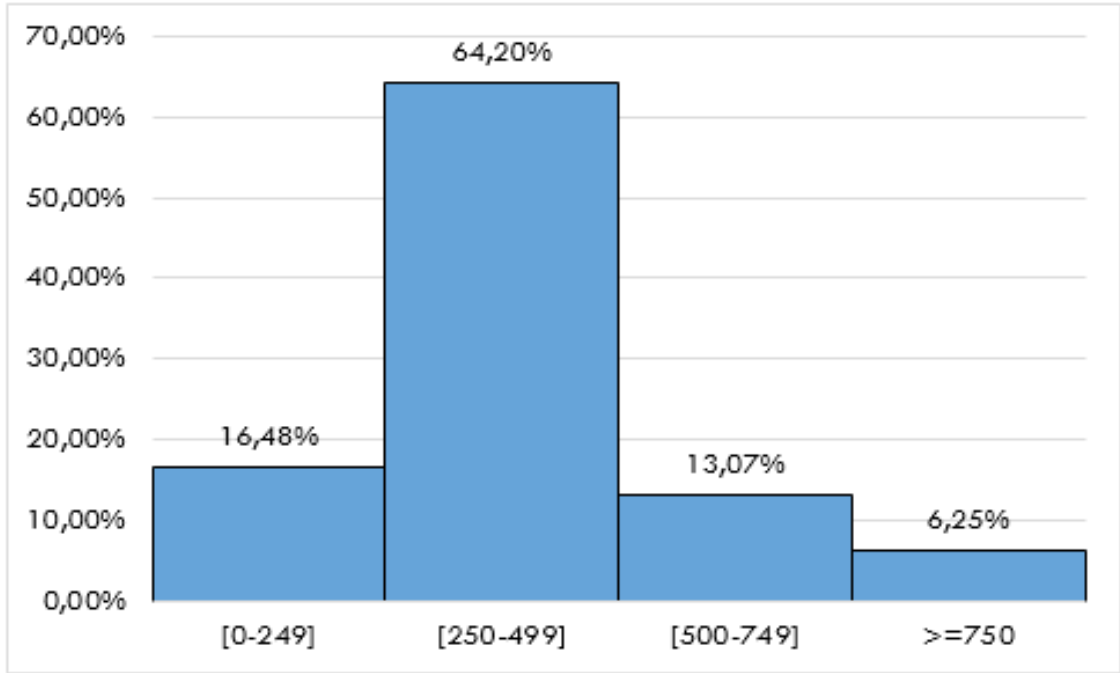

Gráfico 3: Distribuição por classes do gasto médio mensal.

Para realizar uma análise mais específica dos gastos destes alunos da ESTH/IPG obtiveram-se os valores médios mensais gastos em 10 rúbricas (Gráfico 4). Constata-se que as maiores "fatias" dos gastos está concentrada no Alojamento, nas Propinas, na Alimentação e nos Transportes, sendo dinheiro que, na sua maioria ou parcialmente, fica na região. É também de realçar os valores residuais de gastos em Desporto e Cultura, que são duas rúbricas a merecer alguma atenção.

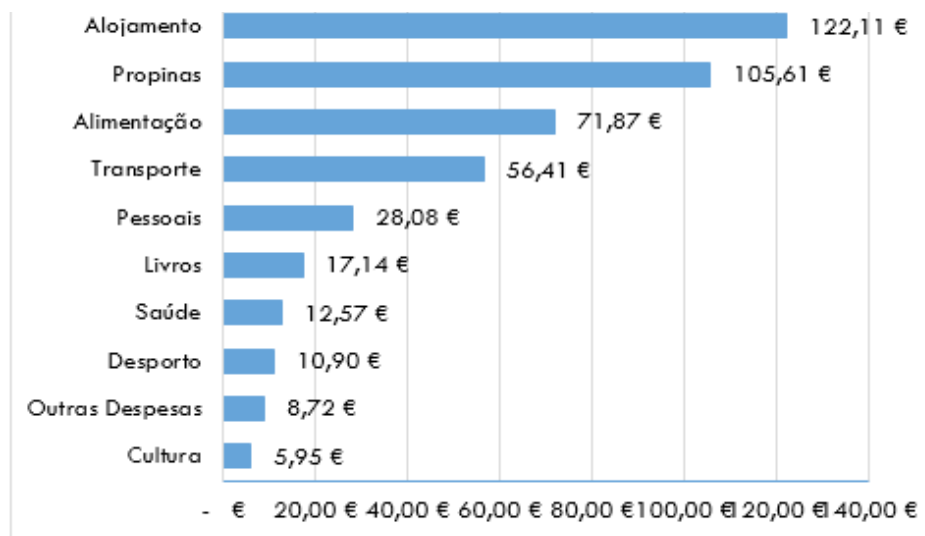

Gráfico 4: Distribuição por classes do gasto médio mensal. 
No que concerne aos gastos com as refeições (Tabela 2), constata-se que os pequenos-almoços (88,1\%), bem como os jantares (92,1\%), ocorrem massivamente em casa dos estudantes. Naturalmente parte, senão mesmo grande parte, dos gastos para a realização destas refeições são realizados na região. O bar da ESTH/IPG surge com uma certa representatividade, nomeadamente ao nível do lanche, mas também nos pequenos-almoços. Os restaurantes são menos referidos, ainda assim apresentam um valor de 5,2\% aos jantares. É também de salientar o facto de que a ESTH/IPG está fechada ao fim de semana, pelo que as refeições não poderão ser realizadas nem na cantina nem no bar.

\begin{tabular}{|l|c|c|c|c|c|c|c|c|}
\cline { 2 - 9 } \multicolumn{1}{c|}{} & \multicolumn{2}{c|}{ Pequeno-almoço } & \multicolumn{2}{c|}{ Almoço } & \multicolumn{2}{c|}{ Lanche } & \multicolumn{2}{c|}{ Jantar } \\
\cline { 2 - 9 } \multicolumn{1}{c|}{} & Frequência & $\%$ & Frequência & $\%$ & Frequência & $\%$ & Frequência & $\%$ \\
\hline Casa & 222 & 88,1 & 97 & 38,5 & 141 & 56,0 & 232 & 92,1 \\
\hline Cantina & & & 109 & 43,3 & & & & \\
\hline Bar & 24 & 9,5 & 81 & 32,1 & 96 & 38,1 & 1 & 0,4 \\
\hline Restaurante & & & 6 & 2,4 & 8 & 3,2 & 13 & 5,2 \\
\hline
\end{tabular}

Tabela 2: Frequência das refeições segundo o local das mesmas.

Relativamente às refeições há ainda a considerar as visitas aos estudantes por parte de familiares e amigos. Assim, apesar de haver 32,8\% dos 189 (75\%) respondentes que indicaram não receber qualquer visita de familiares e/ou amigos, 38,6\% deles indicaram entre uma e quatro visitas por ano e 16,9\% indicaram mais do que dez visitas por ano. Em termos médios, essas vistas são em 42,2\% dos casos de três a quatro pessoas, mas 51,4\% são de uma $(11,9 \%)$ ou duas pessoas $(39,4 \%)$. Em 79,6\% dos casos essas visitas têm uma duração inferior a 24 horas, e as restantes uma duração não superior a 48 horas. Estas visitas de familiares e/ou amigos potenciam também gastos ao nível do comércio local e também, pelo menos parcialmente na região, ao nível dos transportes.

Precisamente no que diz respeito aos transportes, no período de aulas, apenas 16,5 \% dos respondentes indicaram ter que fazer mais de 10km para a escola. A maioria dos alunos (74,4\%) está a menos de 5km de distância da instituição. Na sua deslocação para a escola, os resultados do inquérito mostram que 48,8\% usam transporte próprio (automóvel), 33,7\% usam transporte público e 1,2\% usam Táxi (Tabela 3). 


\begin{tabular}{|c|c|c|}
\hline & Frequência & Percentagem \\
\hline A pé & 26 & 10,3 \\
\hline Transporte público & 85 & 33,7 \\
\hline Transporte próprio & 123 & 48,8 \\
\hline Táxi & 3 & 1,2 \\
\hline Boleia & 63 & 25,0 \\
\hline Outro & 2 & 0,8 \\
\hline
\end{tabular}

Tabela 3: Frequência das várias formas de deslocação de casa para a escola.

O Gráfico 5 agrega resultados sobre o grau de satisfação dos estudantes relativamente a vários aspetos. Neste é de destacar com valores médios superiores a 2,5 (numa escala de 1 a 4) as condições de alojamento e a instituição de ensino (ESTH/IPG), tendo ambas pelo menos $50 \%$ das respostas no espectro do satisfeito ou muito satisfeito (Tabela 4). As acessibilidades apresentam um valor 2,4 (ligeiramente abaixo de 2,5), mas também pelo menos 50\% das respostas estão no espectro do satisfeito ou muito satisfeito. Com valores médios abaixo de 2,5 e com pelo menos 50\% das respostas no espectro do nada ou pouco satisfeito surgem a situação financeira pessoal $(2,21)$, ambiente/vida noturna $(2,23)$ e oferta cultural/desportiva na cidade $(2,12)$. Estes resultados acabam por corroborar alguns dados anteriores, nomeadamente uma percentagem considerável de estudantes com rendimentos disponíveis relativamente baixos e gastos baixos ao nível do desporto e da cultura.

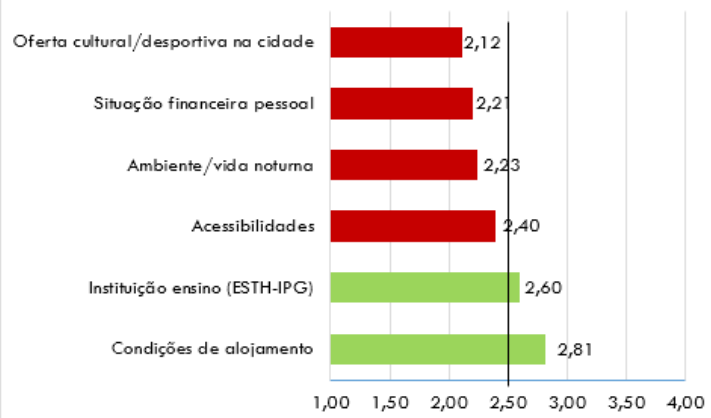

Gráfico 5: Valores médios do grau de satisfação em vários aspetos. 


\begin{tabular}{|c|c|c|c|c|c|c|c|c|c|c|c|c|}
\hline & \multicolumn{2}{|c|}{$\begin{array}{c}\text { Condiçốes } \\
\text { de } \\
\text { alojamento }\end{array}$} & \multicolumn{2}{|c|}{$\begin{array}{c}\text { Oferta } \\
\text { cultural/desportiva } \\
\text { na cidade }\end{array}$} & \multicolumn{2}{|c|}{$\begin{array}{l}\text { Ambiente/ } \\
\text { vida noturna }\end{array}$} & \multicolumn{2}{|c|}{ Acessibilidades } & \multicolumn{2}{|c|}{$\begin{array}{l}\text { Instituição } \\
\text { ensino } \\
\text { (ESTH-IPG) }\end{array}$} & \multicolumn{2}{|c|}{$\begin{array}{l}\text { Situação } \\
\text { financeira } \\
\text { pessoal }\end{array}$} \\
\hline & Freq. & $\%$ & Freq. & $\%$ & Freq. & $\%$ & Freq. & $\%$ & Freq. & $\%$ & Freq. & $\%$ \\
\hline Nada satisfeito & 37 & 16,3 & 55 & 23,9 & 55 & 23,8 & 41 & 17,5 & 46 & 19,0 & 58 & 24,8 \\
\hline Pouco satisfeito & 29 & 12,8 & 96 & 41,7 & 77 & 33,3 & 69 & 29,5 & 40 & 16,5 & 77 & 32,9 \\
\hline Satisfeito & 101 & 44,5 & 76 & 33,0 & 89 & 38,5 & 114 & 48,7 & 120 & 49,6 & 92 & 39,3 \\
\hline Muito satisfeito & 60 & 26,4 & 3 & 1,3 & 10 & 4,3 & 10 & 4,3 & 36 & 14,9 & 7 & 3,0 \\
\hline
\end{tabular}

Tabela 4: Grau de satisfação em relação a vários aspetos.

Na análise do grau de satisfação em relação aos seis aspetos já referidos, com um nível de confiança de 95\%, aplicou-se o teste de independência e a medida de associação para o cruzamento destas variáveis de grau de satisfação com as variáveis género, ano do curso e curso. Encontraram-se diferenças estatisticamente significativas entre os cursos relativamente às condições de alojamento (significância aproximada de 0,045<0,05), notando-se uma maior satisfação por parte dos estudantes do CTeSP. No entanto, o valor V de Cramer, V=0,334, indica que existe uma associação fraca entre as duas variáveis, devido ao seu baixo valor. Foram também encontradas diferenças entre o género relativamente à oferta cultural/desportiva na cidade (com uma significância aproximada de $0,024<0,05)$, onde os mais insatisfeitos parecem ser os estudantes do sexo masculino. Contudo, o valor $V$ de Cramer, $V=0,203$, é baixo e indica que existe uma associação fraca entre as duas variáveis. Existem ainda diferenças entre os géneros relativamente ao ambiente/vida noturna (com uma significância aproximada de $0,013<0,05)$, onde os mais insatisfeitos parecem ser os estudantes do sexo feminino, mas também nesta situação o valor $V$ de Cramer, $V=0,216$, é baixo, indicando uma associação fraca entre as duas variáveis. Em todos os outros casos não foram encontradas quaisquer diferenças estatisticamente significativas.

Outra questão muito importante ao nível do impacto socioeconómico dos estudantes da ESTH/IPG na região é a da capacidade, ou não, da região os conseguir fixar. Como se pode verificar na Tabela 5, foram $12,0 \%$ os que indicaram que, após terminarem o curso, pretendem residir nesta região onde atualmente estudam. Com o apelo das outras regiões de origem responderam $23,4 \%$ enquanto o apelo do estrangeiro é a indicação de 15,5\% dos inquiridos. Existem 21\% dos estudantes 
que responderam ir para onde encontrem emprego. No entanto, há 28,8\% dos inquiridos que indicaram que não sabe/não responde.

\begin{tabular}{|l|c|c|}
\cline { 2 - 3 } \multicolumn{1}{l|}{} & Frequência & Percentagem \\
\hline Sim, se encontrar emprego & 13 & 5,2 \\
\hline Sim, natural da região e não quer mudar & 6 & 2,4 \\
\hline Sim, iá constituiu família nesta região & 4 & 1,6 \\
\hline Sim, pretende continuar a formação na instituição & 7 & 2,8 \\
\hline $\begin{array}{l}\text { Não, pretende regressar à região de onde é na- } \\
\text { tural }\end{array}$ & 59 & 23,4 \\
\hline Não, pretende estudar/trabalhar no estrangeiro & 39 & 15,5 \\
\hline Vai para onde encontrar emprego & 53 & 21,0 \\
\hline Não sabe/não responde & 71 & 28,2 \\
\hline Total & 252 & 100,0 \\
\hline
\end{tabular}

Tabela 5: Frequência sobre a atratividade da região no pós-curso.

Numa análise mais detalhada sobre esta questão, com um nível de confiança de 95\% e utilizando o teste de independência e a medida simétrica o $\mathrm{V}$ de Cramer no cruzamento desta variável com as variáveis género, ano do curso, curso e a proveniência (interior versus litoral), apenas se encontraram diferenças estatisticamente significativas entre os que são do Interior e os do Litoral (significância aproximada de 0,006<0,05). Assim, os alunos provenientes do Litoral mostram maior apetência para regressar à região de onde são naturais, contrariamente aos do Interior, que apresentam maior frequência para ficar na região de Seia, caso encontrem emprego na região. Contudo, o valor V de Cramer, $V=0,281$, indica que existe uma associação fraca entre as variáveis.

\section{CONCLUSÕES}

Com esta investigação de natureza exploratória, pretendia-se caraterizar o perfil socioeconómico dos estudantes de uma UO pertencente a um Instituto Politécnico situado no interior de Portugal, e o impacto dos 
mesmos na cidade e região. Paralelamente procurava-se fazer emergir algumas forças e fraquezas existentes na instituição, bem como eventuais ameaças e oportunidades decorrentes da envolvente.

Relativamente ao perfil dos estudantes, os dados mostram a existência de alguma diversidade sociocultural, tal como já evidenciado noutros estudos (Araújo et al., 2015; Soares et al., 2014). Assim, verifica-se que a faixa etária dos alunos apresenta uma grande amplitude, entre os $17 \mathrm{e}$ os 52 anos. A sua proveniência estende-se por vários distritos do país, com maior incidência nas regiões Centro e Norte, destacando-se os distritos da Guarda, Coimbra e Viseu. Constata-se ainda que a maioria dos alunos possui experiência laboral, alguns deles na área relacionada com o ciclo de estudos que frequentam. Esta situação acaba por se repercutir a vários níveis, nomeadamente na assiduidade e participação desses alunos em algumas unidades curriculares e atividades da instituição, em particular os que possuem o estatuto de trabalhador-estudante.

No que concerne ao nível socioeconómico, os dados permitem estimar que a região possa beneficiar de forma direta, não incluindo o valor das propinas, de um impacto avaliado em mais de 100 mil euros mensais8. O alojamento, a alimentação e os transportes, são as rúbricas com maior relevância. Inversamente, com menor relevância, destacam-se as rúbricas de gastos em desporto e cultura. Esta situação pode revelar uma escassez de oferta cultural e desportiva e/ou falhas na sua divulgação junto da comunidade académica. Nesse sentido, importa implementar uma estratégia que permita melhorar estes indicadores, dado que as expectativas, perceções e grau de satisfação dos alunos, podem ser determinantes para o sucesso da transição, adaptação a uma nova realidade e fixação na região (Araújo et al., 2015, Soares et al., 2014). Contudo, os resultados obtidos mostram que há uma tendência para que alunos dos últimos anos aumentem o nível de gastos globais na região. Este aspeto acaba por ser compreensível, na medida em que conhecem melhor a cidade e a realidade da região envolvente.

Por outro lado não se pode negligenciar a existência de impactos indiretos. Para além da permanência durante os fins de semana de um número significativo de estudantes, há ainda que registar as visitas de

8 O gasto médio por aluno cifrou-se nos $405,08 €$. Considerando os 316 alunos matriculados no ano letivo 2015/2016, perfaz um total de $128005,28 €$. 
familiares e amigos, que potenciam outros gastos, como por exemplo na restauração, no comércio local e na visita a museus.

Quanto ao grau de satisfação dos alunos, verifica-se que as condições de alojamento e a própria instituição de ensino (ESTH-IPG), são aquelas que apresentam valores claramente mais positivos. Estes aspetos são importantes para evitar índices de abandono elevados. Relativamente a aspetos que merecem um maior cuidado e atenção, destacamos as acessibilidades, o ambiente/vida noturna, e a situação financeira pessoal. $O$ indicador claramente menos positivo diz respeito à oferta cultural/desportiva, o que reforça as conclusões referidas anteriormente. Estes aspetos comprovam a necessidade de os municípios e a comunidade envolvente sensibilizarem, investirem e comunicarem as diversas atividades de uma forma eficaz e eficiente, como recurso a formas de comunicação diferentes das tradicionais, como pode ser o caso do recurso a media sociais vs dispositivos móveis.

Os dados mostram também que há um número considerável de alunos que assumidamente pretendem residir e trabalhar na região onde atualmente estudam. Contudo, além destes, há um número significativo que estão disponíveis para residir onde encontrarem emprego. Nesse sentido, a comunidade local e o setor empresarial são fundamentais na integração e fixação destes alunos, criando-Ihes condições sociais e de trabalho que permitam uma aposta nestes, como futuros profissionais. Claramente, isso permitiria um ganho da região em termos de mãode-obra qualificada, num setor estratégico para a economia nacional, regional e local, como é o Turismo.

Em suma, para o caso concreto da UO estudada, a Escola Superior de Turismo e Hotelaria do Instituto Politécnico da Guarda, Iocalizada na cidade de Seia, o problema da captação de novos estudantes e fixação dos mesmos no final dos seus estudos prende-se sobretudo com a falta de atratividade da região (concelho e cidade), ao invés da qualidade do ensino ministrado. É de salientar que os aspetos apontados como menos positivos, são todos externos à própria UO. Assim, parece-nos que é da responsabilidade das instituições/organizações da região, a começar pelo Município, criar e potenciar condições mais atraentes para a vinda e posterior fixação dos estudantes na região. Aspetos como acessibilidades, ambiente/vida noturna e oferta cultural/desportiva, são referenciados como aspetos menos positivos. É 
possível melhorar rapidamente e significativamente estes indicadores, pois são aspetos que estão maioritariamente dependentes dos atores e poder local. Já no que se refere às acessibilidades o problema é mais complexo e difícil de resolução. No entanto, mesmo aqui há possibilidades de melhoria, principalmente no que respeita à mobilidade dentro da própria cidade e concelhos limítrofes (transportes públicos ou outras soluções de mobilidade), bem como os transportes públicos do exterior para a própria cidade.

As situações/soluções apresentadas sabemos que são morosas, complexas e difíceis de resolver/concretizar a curto prazo. Todavia, urge tomar medidas para a sua concretização, pois se nada for feito, a missão desta UO, bem como de outras congéneres, poderá estar seriamente comprometida.

\section{BIBLIOGRAFIA}

Araúio, A. M., Almeida, L. S., Costa, A. R., Alfonso, S., Conde, Á., \& Deaño, M. (2015). Variáveis pessoais e socioculturais de diferenciação das expectativas académicas: Estudo com alunos do Ensino Superior do Norte de Portugal e Galiza. Revista Portuguesa de Educação, 28(1), 201-220.

Cardoso, J. L., Varanda, M., Madruga, P., Escária, V., Ferreira, V. S., \& Raimundo, A. (2012). Empregabilidade e Ensino Superior em Portugal. Lisboa. Retrieved from http://www.ics.ul.pt/publicacoes/workingpapers/wp2012/er2012_1.pdf Carvalho, L., Nunes, S. \& Pinto, S. (2013). Impacto Económico do Instituto Politécnico de Setúbal na Região. Instituto Politécnico de Setúbal.

Fernandes, J. (2009). O Impacto Económico das Instituições de Ensino Superior no Desenvolvimento Regional: O Caso do Instituto Politécnico de Bragança. Dissertação de Doutoramento em Engenharia Económica/Engenharia Industrial e de Sistemas pela Universidade do Minho.

Fernandes, J., Cunha, J., \& Oliveira, P. (2014). O impacto económico do Instituto Politécnico de Bragança no desenvolvimento regional.

Martinho, Alberto Trindade (2017). Seia, de Vila a Cidade. Novel Gráfica - Viseu.

Moura, P. (2014). O Impacto Económico das Instituições de Ensino Superior: A UTAD. Universidade de Trás-os-Montes e Alto Douro.

Oliveira, P., Cunha, J., Silva, J., Lucas, E. \& Nicolau, A. (2012). Caracterização socioeconómica e análise do impacto económico do ano 2012 do Instituto Politécnico de Leiria. Centro de Investigação em Políticas e Sistemas Educativos - 


\section{Egitania}

s c i e $\Omega$ c i a

Instituto Politécnico de Leiria

Pereira, C., Alves, J. \& Mourato, J. (2014). Impacto das Instituições de Ensino Superior no Desenvolvimento Regional: O Caso do Instituto Politécnico de Portalegre. Maria Rego e Tomaz Dentinho (Ed.) - Proceedings of 20th APDR Congress - Renaissance of the Regions of the Southern Europe (pp 293-303). Universidade de Évora.

Pestana, M. H., \& Gageiro, J. N. (2014). Análise de Dados para Ciências Sociais (6th ed.). Edições Sílabo.

Rei, C. M., Daniel, A. C., Lopes, A. I., Braga, A., Castro, E., Marques, F., ... Natário, M. M. (2013). A influência do IPG na região da Guarda - Impacto das Instituições de Ensino Superior no Desenvolvimento Regional. Guarda: Instituto Politécnico da Guarda.

Soares, A. B., Francischetto, V., Dutra, B. M., Miranda, J. M. de, Nogueira, C. C. de C., Leme, V. R., ... Almeida, L. S. (2014). O impacto das expectativas na adaptação acadêmica dos estudantes no Ensino Superior. Psico-USF, 19(1), 49-60. https://doi.org/10.1590/S1413-82712014000100006 